\title{
Elder abuse an international perspective: exploring the context of elder abuse
}

The understanding of elder abuse and neglect, also called elder mistreatment, is at an interesting juncture, both empirically and conceptually. Since 2000 there has been a significant growth in prevalence studies, including major studies from the United Kingdom, Spain, Germany, Ireland, Israel, Finland, Canada, and the United States, with further studies planned in India and Hong Kong (see, for instance, Pillemer and Finkelhor, 1988; McDonald et al., 1991; Comijs et al., 1995; Penhale, 2008; Biggs et al., 2009; Goergen et al., 2009; Lowenstein et al., 2009; Naughton et al. 2010). And while development is still uneven, there is now a World Elder Abuse Awareness Day, held in June every year, with a network of grassroots support in a wide number of countries. At the International Congress of Gerontology and Geriatrics in Bologna, Italy (held on 14-17 April 2011, see http://iaggbologna2011.com), there were, for the first time, six symposia devoted to the topic, and in the Netherlands, a country with some of the first internationally recognized studies, the Leyden Academy in 2011 called the inaugural meeting of an international working group to critically consider interdisciplinary responses to this area of increasing professional concern.

It is arguably the case that the study of elder mistreatment is now coming of age, with a number of studies outlining a close relationship between mistreatment and mental health, well-being, and social adaptation in later life (such as Penhale and Kingston, 1997; Podnieks, 2006; Kurrle and Naughtin, 2008; Lowenstein et al. 2009; Biggs and Haapala, 2010). The WHO (2002a, 2002b) has been influential in establishing the most commonly used definition: "A single, or repeated act, or lack of appropriate action, occurring within any relationship where there is an expectation of trust which causes harm or distress to an older person." This definition is now a standard policy formulation in a variety of fields, countries, and for diverse purposes. The term "abuse" is commonly used to designate acts, and sometimes also negligence, against older persons. Elder mistreatment, also quite regularly used, usually gives a stronger connotation toward the inclusion of neglect, but also covers acts of abuse. Following current standards in the field, both terms are used interchangeably in this special issue.

As the evidence base grows, the field is beginning to develop a conceptual understanding that arises from the phenomenon itself. It is, in other words, casting off positions embedded in other areas, such as child abuse and domestic violence, and, while drawing on these more established fields, is creating one of its own from the dynamics of adult aging and intergenerational relationships. This task is a complex one. As with the rest of psycho-gerontological studies, it is a multidisciplinary area, affecting medical, clinical, psychological, social, institutional, policy, and philosophical concerns. The study of aging has itself not been a policy priority until relatively recently, and then public interest has been centered on questions of demographic changes and a perceived fiscal policy "burden". Research on elder abuse has for the most part been to supply broadly brushed statistical information to stimulate political and policy action.

The contributors to this special edition build on what are beginning to look like increasingly firm scientific foundations. Contributors are included from Australia, Canada, Germany, India, Israel, the Netherlands, Ireland, and the United States, several of whom have led their country's prevalence research and cover disciplines that include medicine, sociology of health, anthropology, critical gerontology, social psychology, criminology, and political science. It is therefore both timely and a significant opportunity to publish a special edition of a journal that both avoids the ghettoization of elder abuse and reflects a growing international interest in attempts to work conceptually across traditional disciplinary and national boundaries.

This attempt has also been enabled by the definitional conformity arising in the past decade. Moreover, following the US National Research Council (2003) report and a number of prevalence studies that have taken cognizance of their guidelines, typologies have become standardized. In general, five forms are distinguished: physical, psychological, financial, sexual abuse, and neglect, further enabling international dialogue. The 
growing number of prevalence studies in the past two decades have built the foundation for this special issue and helped clarify risk factors (Biggs et al., 2009). Taken together, these developments form a more secure foundation for interdisciplinary collaboration.

Elder mistreatment can be seen as both a medical and a social concern. It profoundly impacts the welfare of older adults in their physical wellbeing, both directly by neglect and/or physical violence and indirectly due to psychological abuse or other forms of mistreatment, leaving the person with feelings of marginality, vulnerability, and incompetence. The social perception of mistreatment also acts more broadly in society, shaping expectations of care quality, the surveillance of informal care, and the disciplining of old age. It is then not simply a physical or medical problem of the individual but touches on wider debates affecting a diversity of sciences on the treatment of marginalized groups, the role and legitimacy of the state and professional institutions, and the study of aging and identity.

In this special issue we trace psychosocial elements in interaction with societal components of elder mistreatment to explore its occurrence, reception, and recognition as a problem. Papers in this issue identify the context that enables elder mistreatment and gives leads to what we call "permessors" of elder abuse within different disciplinary, agency, and national contexts. By "permessors" we mean the factors that lead to an increased likelihood that abuse or neglect will happen. These would include an interaction of biological, psychological, and social elements in any given situation. As such they reflect a need to look at the interdependency of events that lead to mistreatment behaviors in both short and longer terms.

As a result, this special issue deals with the welfare and health of older persons in the widest sense of both concepts. It provides the reader with an overview of the field providing international reviews of summative knowledge, the measurement of mistreatment, risk, and attempts to understand how mistreatment has been experienced. It also includes novel research on specific contexts, adding depth to an understanding of the phenomenon. Specifically, we begin the conceptual development from a number of perspectives, including abuse in relation to social ageism, social inclusion, lifecourse experience, interpersonal relations, sociolegal systems, and the nature of perpetrator-victim communication.

Three major themes emerge from this collection. First, there is now a professional and scientific consensus on definitions and core concepts, which aids multidisciplinary comparison (see papers by Goer- gen and Beaulieu, and McDonald and Thomas, and for a more regional overview see paper by Shankardass). These papers show how despite this consensus there are still some challenges to be met when it comes to understanding the underlying causes of mistreatment and forms of relationships that play a role in its occurrence. The second theme addresses a continuing mismatch between the perceptions of the individuals experiencing mistreatment and those who carry the responsibility to respond to it (see, for example, paper by Mysyuk et al.). Moreover, a closer look at the individuals of our target group, older people, shows that even awareness and knowledge of abuse lead to differences in perspectives. Whereas financial abuse and neglect are generally acknowledged in definitions, the experience of this behavior is not always identified as abuse by those exposed to these behaviors even when they have definitional knowledge (see Naughton et al., 2010). This can hamper the recognition and reporting of different forms of mistreatment. These findings can be related to both dynamics of power in relationships and connect with wider social attitudes toward old age, the third theme addressed in this special issue. The implicitness and effects of these predominantly negative attitudes are illustrated by Lin and Giles' exploration of communication about mistreatment in the context of the dynamics of intergenerational relations. Power imbalances and social attitudes also play a role in intergenerational encounters, between older adults themselves, the so-called "resident to resident" abuse (see paper by Ramirez et al.) In this context, exploring the relationship between mistreatment in the light of social ageism and human rights becomes increasingly important (see papers by Biggs and Haapala, and Eiskovits et al.). A relationship between mistreatment, rights, and ageism has been often cited (UN Working Group on the Rights of Older People, 2012), but has rarely been explored systematically. These papers contribute to conceptual clarity in this area.

As we read these novel contributions, the notion of psychological, social, and structural 'permessors' for mistreatment to occur, make sense as a way of integrating disciplinary diversity. When developed more fully, it may provide a platform for common practice while leaving room for specialist expertise to play its role. The identification, recognition, and response to elder mistreatment is emerging as a complex issue where medical, psychological, and social understandings interact. In order to understand such phenomena, conceptual clarity is a must between the clamor of multidisciplinary and wider social and political voices. It is hoped that this collection makes a positive contribution to this continuing debate. 


\section{Conflict of interest}

None.

J. LiNDENBERG, ${ }^{1}$ R. G. J. WeStENDORP, ${ }^{2}$ S. KURRLE $^{3,4}$ AND S. BIGGS ${ }^{5}$

${ }^{1}$ Leyden Academy on Vitality and Ageing and Leiden University, Leiden, the Netherlands

${ }^{2}$ Department of Gerontology and Geriatrics, Leiden University Medical Center and Leyden Academy on Vitality and Ageing, Leiden, the Netherlands

${ }^{3}$ Faculty of Medicine, The University of Sydney, Sydney, Australia

${ }^{4}$ Division of Rehabilitation and Aged Care, Hornsby

Ku-ring-gai Hospital, Sydney, Australia

${ }^{5}$ School of Social and Political Sciences, University of

Melbourne, Melbourne, Australia

Email: Lindenberg@leydenacademy.nl

\section{References}

Biggs, S. and Haapala, I. (2010). Theoretical development and elder mistreatment: spreading awareness and conceptual complexity in examining the management of socio-emotional boundaries. Ageing International, 35, 171-184.

Biggs, S., Erens, B. and Doyle, M. (2009). Abuse and Neglect of Older People: Secondary Analysis of UK Prevalence Study. Report to Department of Health PANCOIA Committee. London: HMSO.

Comijs, H. C., Pot, A. M., Smit, J. H., Bouter, L. M. and Jonker, C. (1998). Elder abuse in the community: prevalence and consequences. Fournal of American Geriatric Society, 46, 885-888.

Goergen, T., Herbst, S., Kotlenga, S., Nägele, B. and Rabold, S. (2009). Crime Experiences and Experiences of Violence in the Lives of Older People. Summary of Major
Events of a Study on Risk of Older and Dependent People. Summay repot of Federal Ministry for Family Affairs, Senior Citizens, Women and Youth, Berlin, Germany (in German).

Kurrle, S. and Naughtin, G. (2008). An overview of elder abuse and neglect. Fournal of Elder Abuse and Neglect, 20, 108-125.

Lowenstein, A., Eiskovits, Z., Band-Winterstein, T. and Enosh, G. (2009). Is elder abuse and neglect a social phenomenon? Data from the first national prevalence survey in Israel. Fournal of Elder Abuse and Neglect, 21, 253-277.

McDonald, L., Hornick, J. P., Robertson, G. P. and Wallace, J. E. (1991). Elder Abuse and Neglect in Canada. Butterworth, UK: Harcourt Brace.

Naughton, C. et al. (2010). Abuse and Neglect of Older People in Ireland. Dublin, Ireland: NCPOP.

Penhale, B. (2008). Elder abuse in the United Kingdom. Fournal of Elder Abuse and Neglect, 20, 151-168.

Penhale, B. and Kingston, P. (1997). Elder abuse, mental health and later life. Aging and Mental Health, 1, 296-304.

Pillemer, K. A. and Finkelhor, D. (1988). The prevalence of elder abuse: a random sample survey. Gerontologist, 28, 51-57.

Podnieks, E. (2006). Social inclusion: an interplay of the determinants of health - new insights into elder abuse. fournal of Gerontological Social Work, 46, 57-79.

UN Working Group on the Rights of Older People. (2012). Normative Standards in International Human Rights Law in Relation to Older Persons. Geneva, Switzerland: OHCHR.

US National Research Council. (2003). In R. J. Bonnie and R. B. Wallace (eds). Elder mistreatment: abuse, neglect, and exploitation in an aging America (Panel to review risk and prevalence of elder abuse and neglect). Washington, DC: The National Academies Press.

WHO. (2002a). The Toronto Declaration on the Global Prevention of Elder Abuse. Geneva, Switzerland: WHO.

WHO. (2002b). The World Report on Violence and Health. Geneva, Switzerland: WHO. 